\title{
Characterization and Development of Genomic SSRs in Pecan (Carya illinoinensis)
}

\author{
Chengcai Zhang ${ }^{1}$, Xiaohua Yao ${ }^{1, *}$, Huadong Ren ${ }^{1}$, Jun Chang ${ }^{1}$, Jun $\mathrm{Wu}^{2}$, Weizhong Shao ${ }^{3}$ and \\ Qing Fang ${ }^{3}$ \\ 1 Research Institute of Subtropical Forestry, Chinese Academy of Forestry, Fuyang District, Hangzhou 311400, \\ China; c.c.zhang@caf.ac.cn (C.Z.); renhd@163.com (H.R.); ylchj163@163.com (J.C.) \\ 2 Jiande Forestry Bureau, Jiande, Hangzhou 311600, China; wujun_jdlyj@163.com \\ 3 Forestry Center of Jiande, Jiande, Hangzhou 311600, China; shaoyunzhu@126.com (W.S.); \\ fangqing_jdlc@163.com (Q.F.) \\ * Correspondence: yaoxh168@163.com; Tel.: +86-571-6331-0094
}

Received: 4 December 2019; Accepted: 2 January 2020; Published: 4 January 2020

\begin{abstract}
Research Highlights: The distribution of simple sequence repeat (SSR) motifs in two draft genomes of pecan was evaluated. Sixty-six SSR loci were validated by PCR amplification in pecan. Twenty-two new development markers can be used for genetic study in genus Carya. Background and Objectives: Pecan has good nutritional and health benefits and is an important crop worldwide. However, the genetic research in this species is insufficient. One of the main reasons for this is the lack of enough accurate, convenient, and economical molecular markers. Among different marker types, SSR loci are enormously useful in genetic studies. However, the number of SSRs in C. illinoinensis (Wangenh.) K. Koch is limited. Materials and Methods: The distribution of SSR motifs in the pecan genome was analyzed. Then, the primers for each SSR were designed. To evaluate their availability, 74 SSR loci were randomly selected and amplified in pecan. Finally, 22 new SSRs and eight former ones were picked to evaluate the genetic diversity in 60 pecan genotypes and to determine their transferability in other Carya species. Results: 145,714 and 143,041 SSR motifs were obtained from two draft genomes of ' $87 \mathrm{MX} 3-2$ ' and 'Pawnee', respectively. In total, 9145 candidate primers were obtained. Sixty-six (89.19\%) primers amplified the target products. Among the 30 SSRs, 29 loci showed polymorphism in 60 pecan genotypes. The polymorphic information content (PIC) values ranged from 0.012 to 0.906 . In total, 26, 25, and 22 SSRs can be used in C. cathayensis Sarg., C. dabieshanensis W. C. Cheng \& R. H. Chang, and C. hunanensis W.C. Liu, respectively. Finally, the dendrogram of all individuals was constructed. The results agree with the geographic origin of the four species and the pedigree relationships between different pecan cultivars. Conclusions: The characterization of SSRs in the pecan genome and the new SSRs will promote the progress of genetic study and breeding in pecan, as well as other species of genus Carya.
\end{abstract}

Keywords: pecan; Carya; SSR; genetic diversity; DNA marker; molecular marker assisted selection

\section{Introduction}

Pecan (Carya illinoinensis (Wangenh.) K. Koch), native to North America, is an important crop worldwide [1]. Pecan nuts are rich in unsaturated fatty acids, phenolics, and flavonoids and have good nutritional and health benefits [2-4]. The nut shell contains high levels of bioactive compounds, including tocopherols, phytosterols, total phenolics, and condensed tannins, and shows antioxidant, antimicrobial, and potential anticancer activity $[5,6]$. Meanwhile, the high oil content $(>70 \%$ of the fresh weight) and high mono-unsaturated fatty acids content of the nut make pecan an excellent oil crop [4]. In addition, the biomass waste of the tree makes pecan a potential energy crop [7]. Previous studies 
have reported a significant variation in phytochemical profiles between different pecan cultivars [8,9]. Therefore, the identity verification and genetic study of this multipurpose tree are important.

To date, several molecular marker types have been used in pecan, such as amplified fragment length polymorphism (AFLP) [10], random amplified polymorphic DNA (RAPD) [11], inter-simple sequence repeat (ISSR) [12], simple sequence repeat (SSR) [13], and single nucleotide polymorphism (SNP) [14]. Compared to the dominant markers (AFLP, RAPD and ISSR), SSRs are superior in terms of their high informative content, high allelic variation, and good reproducibility [15]. They have been extensively employed in genetic diversity, identity verification, kinship analysis, genetic mapping, and association analysis in various plant species [16,17]. In total, 28 SSRs (including 25 genome SSRs and three chloroplast SSRs) have been development in pecan, and a set of 19 SSR loci have been used in genetic diversity studies $[12,13,18,19]$. Li et al. (2014) developed a set of SSRs based on transcriptome sequences of Chinese hickory (C. cathayensis Sarg.) and identified the cross-transferability to other species of Carya; however, the availability of these markers has not been fully evaluated in pecan [20]. Recently, 87,446 SNPs have been discovered in pecan individuals by genotyping by sequencing (GBS), and 17 SNPs were significantly associated with the flowering type [14]. This study significantly promoted the genetic study in genus Carya. However, considering the large information content, high convenience, and low cost of SSR, SNP is unlikely to replace it in the near future $[14,16]$.

Pecan $(2 n=32)$ belongs to the Juglandaceae, with an estimated genome size of approximately $650 \mathrm{Mb}$ [4]. It is a woody plant, which is highly heterozygous and has a lengthy generation time, large plant size, and long juvenile phase [21]. These characteristics inhibited the genetic research and cultivar improvement in this plant. The traditional breeding strategies in this plant are laborious, costly, and time consuming. Recently, molecular marker-assisted selection (MAS) has become a research hotspot in the crop breeding area that can utilize trait-linked markers to shorten the breeding period [22,23]. However, MAS study in pecan is less often carried out. Thereby, MAS in pecan has lagged behind other fruit trees and forestry species [24-27].

In recent years, transcriptome and genome data of pecan have been published $[3,4,28,29]$, offering a good opportunity to discover and develop SSRs on a large scale. Compared to genic SSRs, genomic SSRs (gSSRs) are more abundant [30]. In the present study, the genome sequences of two pecan cultivars, including ' $87 \mathrm{MX} 3-2$ ' and 'Pawnee', were downloaded from public databases. The distribution of SSR motifs in the two cultivars was evaluated. A large number of candidate primers for gSSRs were designed using bioinformatic tools. Then, a set of gSSRs was randomly selected, and evaluated in 'Pawnee' and 'Mahan'. Finally, the gSSRs with a good amplifying effect were picked and then used to analyze the genetic diversity of different types of pecan germplasms in China, and to verify the cross-transferability to three species of the genus Carya. We believe that this study will increase the number of usable SSRs in pecan, and will facilitate genetic diversity study, cultivar identification, genetic mapping, and MAS research in pecan, as well as other species of Carya.

\section{Materials and Methods}

\subsection{Plant Materials and DNA Extraction}

In total, 80 plant samples were used in this study, including 21 pecan cultivars $(20$ cultivars introduced from USA), 14 excellent seedlings, 25 pecan seedling trees, 10 Chinese hickory strains, five C. hunanensis W. C. Cheng \& R. H. Chang seedling trees, and five C. dabieshanensis W.C. Liu seedling trees (Table 1; Figure 1). Genomic DNA was extracted from buds or young leaves of each individual using a Plant DNA Extraction Kit (Tiangen, Beijing, China). All DNA was stored at $-80^{\circ} \mathrm{C}$ until use. 
Table 1. The information about the plant samples.

\begin{tabular}{|c|c|c|c|c|c|c|c|c|c|c|c|c|c|c|}
\hline No. & Name & Species ${ }^{1}$ & Type $^{2}$ & Origin $^{3}$ & No. & Name & Species & Type & Origin & No. & Name & Species & Type & Origin \\
\hline 1 & Osage & C. il & $\mathrm{C}$ & USA & 28 & $\mathrm{~J} 1$ & C. il & ES & Jinhua, ZJ & 55 & JLSX & C. il & SP & Jiande, ZJ \\
\hline 2 & Pawnee & C. il & $\mathrm{C}$ & USA & 29 & $\mathrm{~J} 2$ & C. il & ES & Jinhua, ZJ & 56 & 0071A & C. il & $\mathrm{SP}$ & Jiande, ZJ \\
\hline 3 & McMillan & C. il & $\mathrm{C}$ & USA & 30 & 1101 & C. il & ES & Nanjing, JS & 57 & 0072A & C. il & SP & Jiande, ZJ \\
\hline 4 & Lakota & C. il & $\mathrm{C}$ & USA & 31 & 1103 & C. il & ES & Nanjing, JS & 58 & 0073A & C. il & SP & Jiande, ZJ \\
\hline 5 & Carter & C. il & $\mathrm{C}$ & USA & 32 & 1104 & C. il & ES & Nanjing, JS & 59 & SDHD1 & C. il & SP & Jiande, ZJ \\
\hline 6 & Colby & C. il & $\mathrm{C}$ & USA & 33 & 1106 & C. il & ES & Nanjing, JS & 60 & SDHDX1 & C. il & SP & Jiande, ZJ \\
\hline 7 & Stuart & C. il & $\mathrm{C}$ & USA & 34 & 1201 & C. il & ES & Nanjing, JS & 61 & JP-18 & C. hu & SP & Jinping, GZ \\
\hline 8 & Greenriver & C. il & $\mathrm{C}$ & USA & 35 & 1202 & C. il & ES & Nanjing, JS & 62 & JP-17 & C. hu & SP & Jinping, GZ \\
\hline 9 & Waco & C. il & $\mathrm{C}$ & USA & 36 & JL72 & C. il & SP & Jiande, ZJ & 63 & JP-19 & C. hu & SP & Jinping, GZ \\
\hline 10 & Major & C. il & $\mathrm{C}$ & USA & 37 & JL72D & C. il & SP & Jiande, ZJ & 64 & JP-20 & C. hu & $\mathrm{SP}$ & Jinping, GZ \\
\hline 11 & Oconee & C. il & $\mathrm{C}$ & USA & 38 & JL1 & C. il & SP & Jiande, ZJ & 65 & JP-18 & C. hu & SP & Jinping, GZ \\
\hline 12 & Syrup Mill & C. il & $\mathrm{C}$ & USA & 39 & JL2 & C. il & SP & Jiande, ZJ & 66 & TTZ-15 & C. da & SP & Luan, $\mathrm{AH}$ \\
\hline 13 & Navaho & C. il & $\mathrm{C}$ & USA & 40 & JL3 & C. il & SP & Jiande, ZJ & 67 & TTZ-21 & C. da & SP & Luan, $\mathrm{AH}$ \\
\hline 14 & Gloria Grande & C. il & $\mathrm{C}$ & USA & 41 & JL00011 & C. il & SP & Jiande, ZJ & 68 & TTZ-20 & C. da & $\mathrm{SP}$ & Luan, $\mathrm{AH}$ \\
\hline 15 & Forkert & C. il & $\mathrm{C}$ & USA & 42 & SD1-2 & C. il & SP & Jiande, ZJ & 69 & TTZ-22 & C. da & SP & Luan, $\mathrm{AH}$ \\
\hline 16 & Choctaw & C. il & $\mathrm{C}$ & USA & 43 & $\mathrm{SJ} 2$ & C. il & SP & Jiande, ZJ & 70 & TTZ-11 & C. da & SP & Luan, $\mathrm{AH}$ \\
\hline 17 & Creek & C. il & $\mathrm{C}$ & USA & 44 & SJ1 & C. il & SP & Jiande, ZJ & 71 & GL2 & C. ca & $\mathrm{S}$ & Jinhua, ZJ \\
\hline 18 & Mohawk & C. il & $\mathrm{C}$ & USA & 45 & YZXT & C. il & SP & Jiande, ZJ & 72 & XK24 & C. ca & $S$ & Jinhua, ZJ \\
\hline 19 & Elliott & C. il & $\mathrm{C}$ & USA & 46 & YZXD & C. il & SP & Jiande, ZJ & 73 & DY1 & C. ca & $S$ & Jinhua, ZJ \\
\hline 20 & Mahan & C. il & $\mathrm{C}$ & USA & 47 & YZXG1 & C. il & SP & Jiande, ZJ & 74 & DY6 & C. ca & $\mathrm{S}$ & Jinhua, ZJ \\
\hline 21 & YLC21 & C. il & $\mathrm{C}$ & Jiande, ZJ & 48 & YZXG2 & C. il & SP & Jiande, ZJ & 75 & GL8 & C. ca & S & Jinhua, ZJ \\
\hline 22 & XH1 & C. il & ES & Hangzhou, ZJ & 49 & JL4 & C. il & SP & Jiande, ZJ & 76 & XK88 & C. ca & $S$ & Jinhua, ZJ \\
\hline 23 & $\mathrm{XH} 4$ & C. il & ES & Hangzhou, ZJ & 50 & CHK1 & C. il & SP & Hangzhou, ZJ & 77 & DY5 & C. ca & $S$ & Jinhua, ZJ \\
\hline 24 & XH5 & C. il & ES & Hangzhou, ZJ & 51 & CHK2 & C. il & SP & Hangzhou, ZJ & 78 & GL7 & C. ca & S & Jinhua, ZJ \\
\hline 25 & XH6 & C. il & $\mathrm{ES}$ & Hangzhou, ZJ & 52 & CHK3 & C. il & SP & Hangzhou, ZJ & 79 & XK89 & C. ca & S & Jinhua, ZJ \\
\hline 26 & XH14 & C. il & ES & Hangzhou, ZJ & 53 & CHK4 & C. il & SP & Hangzhou, ZJ & 80 & XK40 & C. ca & $S$ & Jinhua, ZJ \\
\hline 27 & $\mathrm{DFH}$ & C. il & ES & Jinhua, ZJ & 54 & JLCD & C. il & SP & Jiande, ZJ & & & & & \\
\hline
\end{tabular}

Note: ${ }^{1}$ C.il $=$ C. illinoinensis, C. ca $=$ C. cathayensis, C. da $=$ C. dabieshanensis, C. hu $=$ C. hunanensis $;{ }^{2} \mathrm{C}=$ Cultivar, ES $=$ Excellent seedling, $\mathrm{S}=\mathrm{Strain}, \mathrm{SP}=\mathrm{Seeding}$ plant; ${ }^{3} \mathrm{ZJ}=\mathrm{Zhejiang}$ province, $\mathrm{GZ}=$ Guizhou province, $\mathrm{JS}=$ Jiangsu province. 


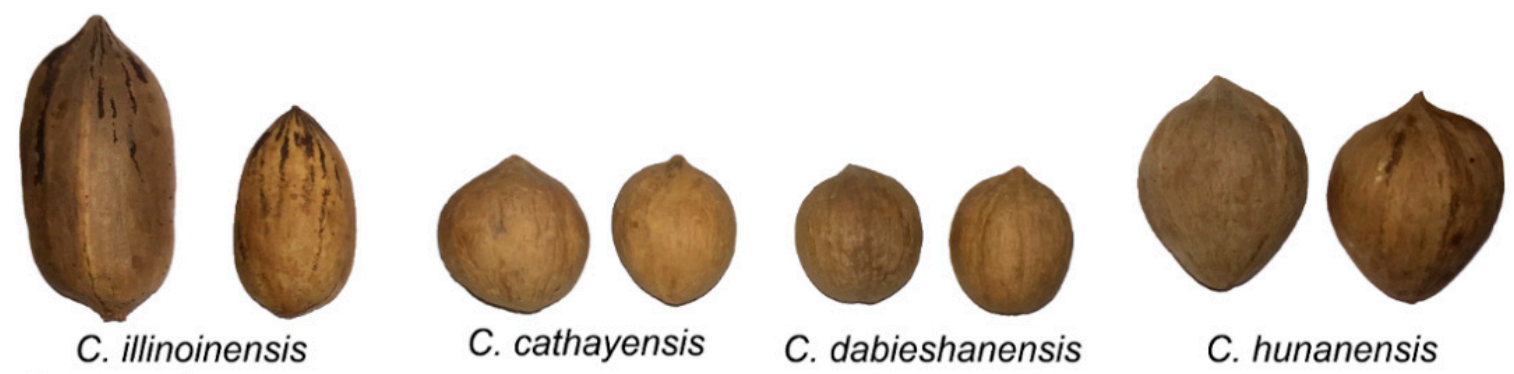

Figure 1. The nuts of four Carya species. The scale is one centimeter.

\section{2. gSSR Mining and Primer Design}

The genomic sequences of '87MX3-2' (http://www.hagsc.org/pecan) and 'Pawnee' (ftp://parrot. genomics.cn/gigadb/pub/10.5524/100001_101000/100571/) were downloaded from public databases, respectively. The Microsatellite identification tool (MISA, http://pgrc.ipk-gatersleben.de/misa/misa. $\mathrm{html}$ ) was used to search SSR motifs in the genome of each cultivar (Thiel et al., 2003), with repeats with a minimum of $6,5,5,5$, and 5 for di-, tri-, tetra-, penta-, and hexanucleotides, respectively. For compound SSRs, the maximum interruption between two SSRs was set as 100 bases. Primers for the SSR loci were designed using p3_in.pl, primer3_core, and p3_out.pl programs under default parameters (Untergasser et al., 2012). Then, the low-quality primer pairs were subsequently removed, such as those featuring the following: (1) the primers containing unknown bases; (2) a $3^{\prime}$ end of primers with three consecutive identical bases; (3) a Tm value difference between forward and reverse primers of more than $1{ }^{\circ} \mathrm{C}$; (4) a GC content of each primer $>55 \%$ or $<35 \%$; (5) the ratio of GC content between forward and reverse primers of $>1.2$ or $<0.8$.

\subsection{Amplification and Validation of $g S S R s$}

A total of 74 gSSR loci were randomly selected. Genomic DNA from 'Pawnee' and 'Mahan' were selected to amplify target products and validate the usability of these primers. PCR reactions were performed in $16 \mu \mathrm{L}$ reaction volumes, containing $7.5 \mu \mathrm{L}$ of $2 \times$ Tsingke Master mix (Beijing Tsingke Biological Technology Co., Ltd., Beijing, China), $1 \mu \mathrm{L}$ of each primer (10 pmol), and $1 \mu \mathrm{L}$ of cDNA

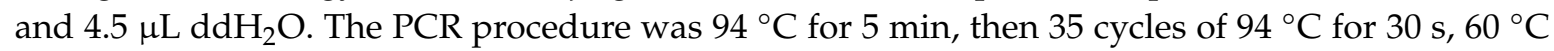
for $30 \mathrm{~s}, 72{ }^{\circ} \mathrm{C}$ for $30 \mathrm{~s}$, with a final extension at $72{ }^{\circ} \mathrm{C}$ for $5 \mathrm{~min}$. PCR products were electrophoresed using $1 \%$ agarose under $300 \mathrm{~V}$ for $12 \mathrm{~min}$. The primers which amplify the expected product size were selected and labeled with HEX, ROX, FAM, or TRAMA. The PCR amplifications were performed again, and the products were separated using capillary electrophoresis on an ABI 3730 sequencer (Applied Biosystems, Forster City, CA, USA). Finally, the primers that gave clearly distinguishable peaks were used for the genetic study of the pecan population.

\subsection{Genetic Diversity Analysis of Pecan and Transferability of gSSRs to Other Species}

Twenty-two validated gSSRs and eight SSRs from Grauk et al. (2003) were chosen to amplify genomic DNA from 80 genotypes [13]. PCR products from each individual were separated using capillary electrophoresis. The genotype of each SSR locus was analyzed by Gene Mapper 4.1 software (Applied Biosystems, Foster City, CA, USA). Several genetic parameters, including observed allele number $(\mathrm{Na})$, observed heterozygosity $(\mathrm{Ho})$, expected heterozygosity $(\mathrm{He})$, and polymorphic information content (PIC), were calculated by using the Popgen 32 program (University of Alberta and Center for International Forestry Research, Canada). A phylogenetic dendrogram was constructed by using the unweighted pair group method with arithmetic average (UPGMA). 


\section{Results}

\subsection{Characteristics of $g S S R s$}

The genomic sequences of '87MX3-2' and 'Pawnee' were downloaded and analyzed using the MISA program. The results showed that 48,009 (38.54\%) out of 124,560 scaffolds (531.7 Mb) of ' $87 \mathrm{MX} 3-2$ ' were found to contain SSR motifs (Table 2). In total, 145,714 gSSRs were confirmed (Table S1). So, the frequency of gSSR in '87MX3-2' was 1 gSSR per $3.65 \mathrm{~kb}$. Among different types of SSR motifs, the dinucleotide $(121,626,83.47 \%)$ was the most predominant, followed by trinucleotide $(18,593,12.76 \%)$ (Figure 2). For the dinucleotide repeat motif, AT/TA (53.60\%) was the main type, while CG/GC (0.21\%) was the least frequent. In total, 143,041 gSSRs were identified in 4955 (11.47\% out of 43,183 examined sequences) sequences in the genome of 'Pawnee' (651.2 Mb; Table S1). The frequency of gSSR is 1 gSSR per $4.55 \mathrm{~kb}$. Dinucleotide repeat motifs $(118,045,82.53 \%)$ formed the main category, followed by trinucleotide $(19,818,13.85 \%)$. The most and the least present types of dinucleotide repeat motif were AT/TA (48.22\%) and CG/GC (0.22\%), respectively.

Table 2. Information of simple sequence repeats (SSRs) identified in the pecan genome.

\begin{tabular}{ccc}
\hline \multirow{2}{*}{ Features } & \multicolumn{2}{c}{ Values } \\
\cline { 2 - 3 } & '87MX3-2' & 'Pawnee' \\
\hline Total number of sequences examined & 124,560 & 43,183 \\
Total size of examined sequences (bp) & $531,741,495$ & $651,240,950$ \\
Total number of identified SSRs & 145,714 & 143,041 \\
Number of SSR containing sequences & 48,009 & 4955 \\
Number of sequences containing more than 1 SSR & 27,045 & 1961 \\
Number of SSRs present in compound formation & 21,060 & 17,816 \\
\hline
\end{tabular}

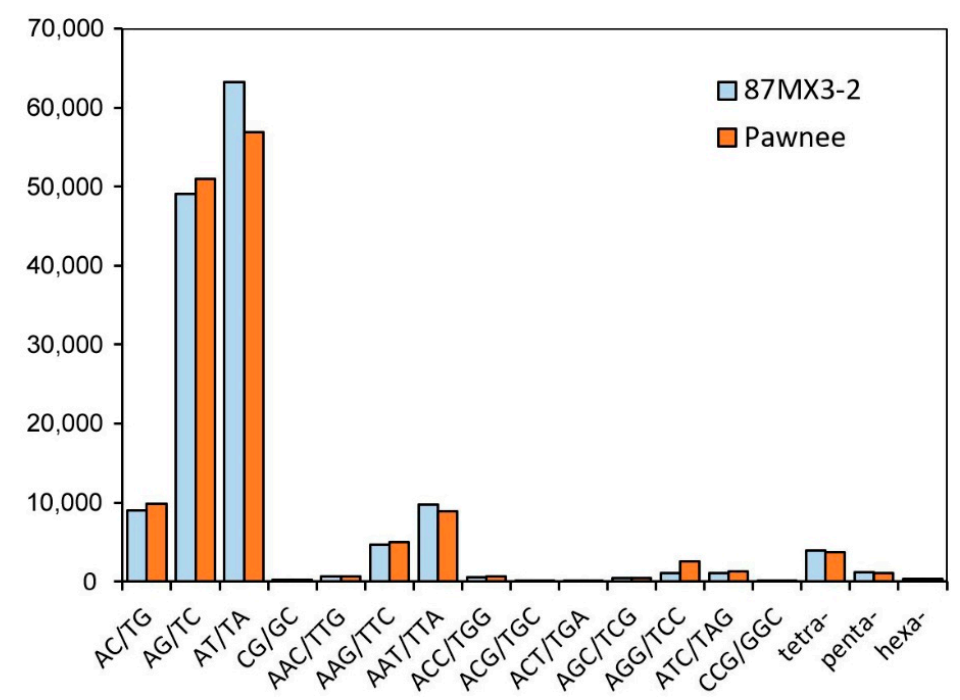

Figure 2. The motif distribution pattern of pecan genomic simple sequence repeats (gSSRs) (considering sequence complementary).

\subsection{Primer Design and Validation}

A total of 60,018 primer pairs for 20,006 gSSRs in 7143 sequences were designed by using Primer 3 software (Whitehead Institute, Cambridge, MA, USA). Then, 9145 (15.24\%) candidate primer pairs to 5002 gSSRs (25.00\%) were obtained after the deletion of low-quality ones (Table S2). To validate this, a set of 74 primer pairs were randomly picked and synthesized. All of them were distributed in 74 contigs of '87MX3-2' genome sequences. These loci were distributed in 70 scaffolds of 'Pawnee' genome sequences: Ciz034 and Ciz035 in scaffold72459, Ciz037 and Ciz058 in scaffold69125, Ciz039 and Ciz044 
in scaffold101014, and Ciz065 and Ciz074 in scaffold89570. To validate these markers, the 74 primers were amplified in 'Pawnee' and 'Mahan'. After electrophoresis, 66 primer pairs (89.19\%) yielded the expected bands (Table S3). The size of amplicons ranged from $111 \mathrm{bp}$ (Ciz028) to $280 \mathrm{bp}$ (Ciz006). Six loci (Ciz018, Ciz032, Ciz042, Ciz063, Ciz064, and Ciz065) had no PCR product observed. Two loci (Ciz012 and Ciz026) obtained a nontarget product.

\subsection{Genetic Diversity Analysis and Cross-Species Transferability of gSSRs}

Twenty-two randomly selected gSSRs from 66 validated loci and eight SSRs from a previous study were employed in this section (Table 3) [13]. In total, 60 pecan genotypes and 20 individuals from three other species were used to perform genetic diversity analysis and cross-transferability, respectively. The PCR products were separated using capillary electrophoresis (Figure 3). Among the 22 newly developed gSSR loci, 21 (95.45\%, except Ciz036) exhibited polymorphism in the examined population (Table 3). For all loci, the observed allele number (Na) ranged from 1 (Ciz036) to 18 (Ciz031). A total of 221 alleles were detected in pecan, and the mean number of alleles per locus was 7.369. The observed heterozygosity ranged from 0.00 (Ciz036) to 1 (Ciz047) with a mean value of 0.439 . In addition, the minimum and the maximum of PIC values were 0.00 (Ciz036) and 0.893 (Ciz031), with 23 loci showing high PIC values (PIC > 0.5), and the mean value was 0.547 . Twenty-six ( $86.67 \%$ ) gSSRs could yield the target product in hickory, while $25(83.33 \%)$ and $22(73.33 \%)$ loci could be used in C. dabieshanensis and C. hunanensis, respectively (Table 4).

Table 3. The genetic characteristics of 30 SSR loci in 60 pecan genotypes.

\begin{tabular}{|c|c|c|c|c|c|c|c|}
\hline NO. ${ }^{1}$ & Loci & Fluorescence Dye & $\mathrm{Na}^{2}$ & $\mathrm{Ho}^{3}$ & $\mathrm{He}^{4}$ & PIC $^{5}$ & Size (bp) \\
\hline 1 & Ciz003 & ROX & 10 & 0.695 & 0.741 & 0.735 & $137-178$ \\
\hline 2 & Ciz009 & ROX & 5 & 0.525 & 0.517 & 0.513 & $157-163$ \\
\hline 3 & Ciz011 & ROX & 2 & 0.068 & 0.097 & 0.096 & $202-204$ \\
\hline 4 & Ciz022 & FAM & 5 & 0.650 & 0.630 & 0.625 & $223-237$ \\
\hline 5 & Ciz031 & FAM & 18 & 0.542 & 0.901 & 0.893 & $237-257$ \\
\hline 6 & Ciz036 & TRAMA & 1 & 0.000 & 0.000 & 0.000 & 264 \\
\hline 7 & Ciz038 & HEX & 3 & 0.300 & 0.551 & 0.546 & $213-216$ \\
\hline 8 & Ciz039 & ROX & 4 & 0.200 & 0.390 & 0.387 & 198-202 \\
\hline 9 & Ciz040 & FAM & 5 & 0.367 & 0.475 & 0.471 & $219-227$ \\
\hline 10 & Ciz043 & TRAMA & 14 & 0.712 & 0.800 & 0.793 & $260-278$ \\
\hline 11 & Ciz045 & FAM & 6 & 0.224 & 0.549 & 0.544 & $182-253$ \\
\hline 12 & Ciz046 & FAM & 12 & 0.237 & 0.755 & 0.748 & $250-262$ \\
\hline 13 & Ciz047 & FAM & 5 & 1.000 & 0.646 & 0.641 & $236-241$ \\
\hline 14 & Ciz050 & FAM & 3 & 0.070 & 0.102 & 0.101 & $243-261$ \\
\hline 15 & Ciz052 & ROX & 9 & 0.517 & 0.601 & 0.596 & $203-223$ \\
\hline 16 & Ciz055 & TRAMA & 16 & 0.690 & 0.899 & 0.891 & $249-268$ \\
\hline 17 & Ciz058 & FAM & 13 & 0.550 & 0.807 & 0.801 & 199-247 \\
\hline 18 & Ciz059 & TRAMA & 7 & 0.633 & 0.708 & 0.702 & $232-265$ \\
\hline 19 & Ciz070 & TRAMA & 12 & 0.695 & 0.824 & 0.817 & $265-280$ \\
\hline 20 & Ciz071 & TRAMA & 5 & 0.817 & 0.751 & 0.744 & $269-273$ \\
\hline 21 & Ciz073 & TRAMA & 5 & 0.390 & 0.512 & 0.507 & $273-285$ \\
\hline 22 & Ciz074 & ROX & 3 & 0.339 & 0.333 & 0.330 & 180-186 \\
\hline 23 & PM-CA10 & HEX & 2 & 0.051 & 0.050 & 0.050 & $92-113$ \\
\hline 24 & PM-CIN13 & HEX & 6 & 0.441 & 0.510 & 0.506 & $102-116$ \\
\hline 25 & PM-CIN20 & ROX & 2 & 0.017 & 0.017 & 0.016 & 139-142 \\
\hline 26 & PM-CIN22 & HEX & 5 & 0.117 & 0.590 & 0.585 & 96-103 \\
\hline 27 & PM-CIN27 & HEX & 12 & 0.800 & 0.775 & 0.768 & $62-92$ \\
\hline 28 & PM-CIN4 & HEX & 16 & 0.783 & 0.796 & 0.789 & $90-143$ \\
\hline 29 & PM-GA38 & HEX & 9 & 0.627 & 0.602 & 0.596 & $81-100$ \\
\hline 30 & PM-GA41 & HEX & 6 & 0.105 & 0.637 & 0.631 & 69-90 \\
\hline- & Mean & - & 7.367 & 0.439 & 0.552 & 0.547 & - \\
\hline- & St. Dev & - & 4.752 & 0.283 & 0.266 & 0.264 & - \\
\hline
\end{tabular}

Note: ${ }^{1}$ The SSR loci of 23 30 from a previous study [13]; ${ }^{2} \mathrm{Na}=$ observed allele number; ${ }^{3}$ Ho $=$ observed heterozygosity; ${ }^{4} \mathrm{He}=$ expected heterozygosity; and ${ }^{5} \mathrm{PIC}=$ polymorphic information content. 


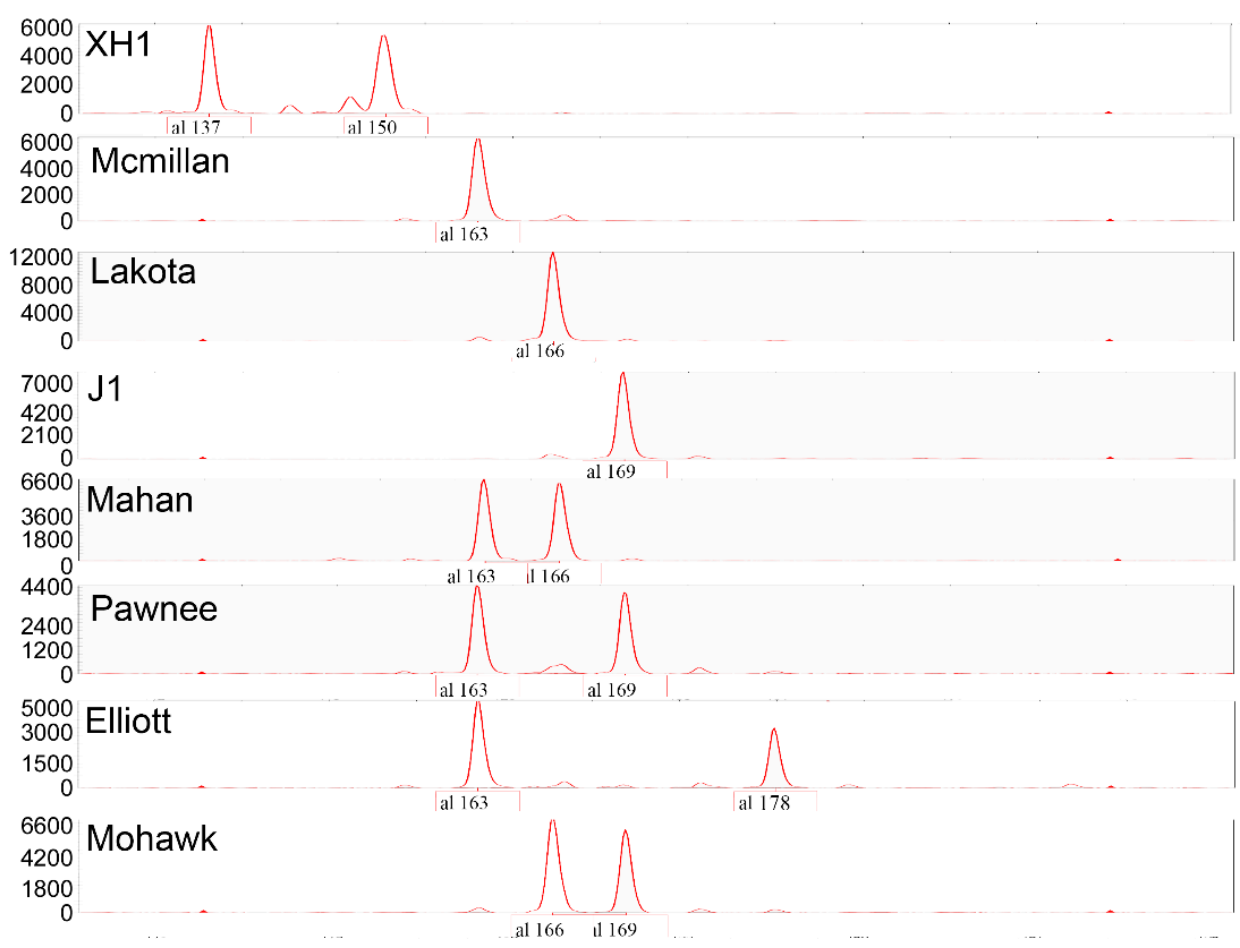

Figure 3. The capillary electrophoresis patterns of primer Ciz003 in eight pecan germplasms.

Table 4. The cross-transferability of 30 SSR loci in three species.

\begin{tabular}{|c|c|c|c|c|c|c|}
\hline \multirow{2}{*}{ Locus } & \multicolumn{2}{|c|}{ C. cathayensis $(n=10)$} & \multicolumn{2}{|c|}{ C. dabieshanensis $(n=5)$} & \multicolumn{2}{|c|}{ C. hunanensis $(n=5)$} \\
\hline & $\mathrm{Na}$ & Size (bp) & $\mathrm{Na}$ & Size (bp) & $\mathbf{N a}$ & Size (bp) \\
\hline Ciz003 & - & - & - & - & - & - \\
\hline Ciz009 & 1 & 167 & 1 & 167 & 2 & $167-176$ \\
\hline Ciz011 & 1 & 203 & 1 & 203 & 1 & 203 \\
\hline Ciz022 & 2 & $228-230$ & 1 & 228 & 1 & 230 \\
\hline Ciz031 & 2 & $249-255$ & 3 & $252-255$ & 1 & 253 \\
\hline Ciz036 & 1 & 264 & 1 & 264 & 1 & 264 \\
\hline Ciz038 & 2 & $216-218$ & 1 & 218 & - & - \\
\hline Ciz039 & 1 & 199 & 3 & 195-202 & 2 & 196-197 \\
\hline Ciz040 & 1 & 222 & 1 & 222 & 2 & $216-222$ \\
\hline Ciz043 & 1 & 260 & 1 & 260 & 2 & $260-261$ \\
\hline Ciz045 & 6 & $205-227$ & 4 & $205-224$ & 1 & 224 \\
\hline Ciz046 & - & - & - & - & - & - \\
\hline Ciz047 & 1 & 238 & 2 & $238-241$ & 2 & $238-241$ \\
\hline Ciz050 & 4 & 239-254 & 2 & $230-240$ & 2 & $222-240$ \\
\hline Ciz052 & 3 & $251-255$ & 1 & 254 & 1 & 254 \\
\hline Ciz055 & 1 & 263 & 1 & 263 & 3 & $260-264$ \\
\hline Ciz058 & - & - & 3 & $233-241$ & - & - \\
\hline Ciz059 & 2 & $266-267$ & 2 & $264-267$ & 1 & 264 \\
\hline Ciz070 & - & - & - & - & - & - \\
\hline Ciz071 & 2 & $255-266$ & 2 & $255-266$ & 2 & $255-266$ \\
\hline Ciz073 & 4 & $266-270$ & 1 & 270 & 2 & $267-270$ \\
\hline Ciz074 & 3 & 175-180 & 3 & 177-183 & - & - \\
\hline PM-CA10 & 1 & 134 & 3 & $116-136$ & - & - \\
\hline PM-CIN13 & 3 & 104-111 & - & - & - & - \\
\hline PM-CIN20 & 1 & 139 & 1 & 139 & 1 & 139 \\
\hline PM-CIN22 & 1 & 95 & 1 & 95 & 1 & 94 \\
\hline PM-CIN27 & 2 & $62-66$ & - & - & 1 & 68 \\
\hline PM-CIN4 & 3 & 113-118 & 2 & $113-114$ & 2 & 105-118 \\
\hline PM-GA38 & 2 & 80-90 & 2 & 80-82 & 2 & $82-92$ \\
\hline PM-GA41 & 2 & 95-101 & 1 & 101 & 1 & 99 \\
\hline
\end{tabular}




\subsection{Population Structure and Cluster Analysis}

The 80 individuals were mainly divided into two clusters (Figure 4). Cluster I contained all samples originating from China, including 10 hickory, five C. dabieshanensis, and five C. hunanensis. According to three different species, cluster I was divided into three subclasses. The genetic distance between hickory and $C$. dabieshanensis was relatively close. The samples of pecan were clustered together and showed two subclasses. Interestingly, all the cultivars and most excellent strains (10 out of 14) were classified together, while nearly all the seedling trees (21 out of 25) and four excellent strains were clustered into another subgroup. Nine cultivars ('Mohawk', 'Forkert', 'Oconee', 'Choctaw', 'Mahan', 'Osage', 'Waco', 'Pawnee', and 'Creek') and three excellent strains (1101, XH5, and XH6) appeared to have a short genetic distance. In addition, 'Colby', 'Carter', 'Syrup Mill', 'Gloria Grande', and 'Stuart'; 'Major', 'Lakota', and 'Greenriver'; and 'Elliott' and 'Navaho' were clustered together, respectively (Figure 4).

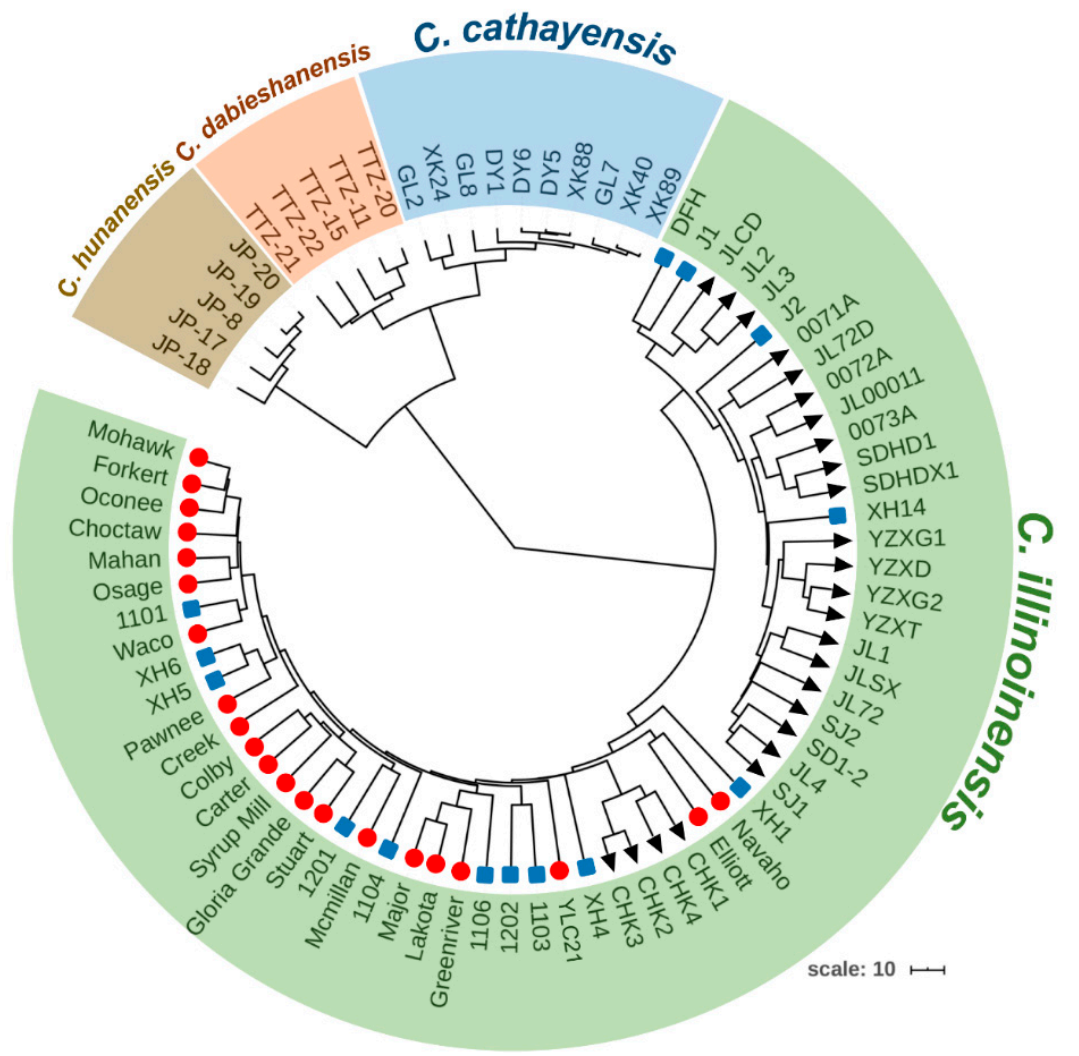

Figure 4. The dendrogram of 80 germplasms constructed by the unweighted pair group method with arithmetic average (UPGMA). The plant samples included 60 C. illinoinensis, 10 C. cathayensis, five $C$. dabieshanensis, and five $C$. hunanensis. The positions of cultivars, strains, and seeding plants of pecan are indicated by red circles, blue squares, and black triangles.

\section{Discussion}

Recently, next and third-generation sequencing technologies have been employed to investigate molecular mechanisms of key traits and construct a reference genome in pecan $[3,4,12,28]$. Transcriptomes and draft genomes offered an opportunity to identify SSR sites on a large scale. In the present study, two draft genomes of '87MX3-2' and 'Pawnee' were independently analyzed to mine genomic SSR loci [14,28]. The frequencies of the occurrence of gSSRs were $1 / 3.65 \mathrm{~kb}$ and $1 / 4.55 \mathrm{~kb}$ in '87MX3-2' and 'Pawnee', respectively. The gSSR densities between two cultivars showed slight differences. The genomic SSR frequency was significantly higher than genic SSR (1/6.10 kb; 6860 SSRs, including di-, tri-, tetra-, penta-, and hexanucleotides, in 41,858,722 bp sequences) in 
pecan [29], which confirmed that the gSSR is more abundant than transcriptomic SSRs in this plant. The gSSR density is higher than bamboo (1 SSR/16 kb) [31], and lower than walnut (1 SSR/2.3 kb) and Chinese jujube (1 SSR/1.17 kb) [32,33]. Among dinucleotide repeat motifs, AT/TA was the most abundant type, followed by AG/TC (Figure 2). This result was similar to gSSRs in Chinese Jujube and cumin $[15,34]$. Sixty-six $(89.19 \%)$ out of 74 primers were successfully validated by using PCR in two cultivars (Table S3). The success rate was similar to Cyamopsis tetragonoloba (86.4\%) [35], higher than Camellia sinensis $(32.00 \%)$ and Exbucklandia tonkinensis $(76.26 \%)[30,36]$.

The genus Carya consists of 17 species [1], of which pecan, hickory, C. hunanensis, and C. dabieshanensis have significant economic values in China [3]. However, the molecular markers in these species are far from sufficient. In this study, 66 gSSRs were validated in 'Pawnee' and 'Mahan', and 21 newly developed loci and eight previous SSRs showed genetic polymorphisms in different germplasms (Table 3). Among them, 23 loci showed high PIC values (>0.5). Therefore, these gSSR loci exhibited high polymorphisms in different germplasms and could be used in genetic diversity study, genetic map construction, Quantitative trait loci (QTL) mapping, as well as cultivar identification in pecan. For the cross-transferability of gSSR loci, 86.67\% (26/30) of gSSRs can be used in hickory, which was higher than that in a previous study $(63.02 \%)$ [20]. Moreover, the transferability rates were $83.33 \%$ (25/30) and 73.33\% (22/30) between pecan and two other Carya species of C. dabieshanensis and C. hunanensis, respectively (Table 4). Similarly, high transferability rates also have been reported in other species, such as Pistacia vera L. [37], Casuarina L. ex Adans [38], and Melilotus [39].

SSR is a useful tool for evolutionary studies and pedigree relationships evaluation [16]. As is shown in Figure 4, the species of C. hunanensis, C. dabieshanensis, and C. cathayensis were clustered together, and the last two species showed a closer relationship. These observations are consistent with the results of Zhang et al. (2013), who reported that the Carya species from eastern Asian and eastern North American were classified into two different groups, respectively [40]. For pecan, 'Mohawk', 'Forkert', 'Oconee', 'Choctaw', 'Mahan', 'Osage', 'Waco', 'Pawnee', and 'Creek' exhibited a wide range of similarities. Similar results were also reported by previous studies [12,13]. 'Mohawk' and 'Choctaw' originated from a controlled cross of 'Success' $\times$ 'Mahan' [14,41] (Table S4), and 'Mohawk' was the parent of 'Pawnee' and 'Creek'. 'Forkert' was selected from offspring of 'Success' $\times$ 'Schley' [14,41]. 'Schley' was an ancestor of 'Oconee' and 'Waco' [41]. Therefore, these individuals have pedigree relationships with each other, and the group patterns agreed with this fact. Incidentally, '1101', 'XH5', and ' $\mathrm{XH6}^{\prime}$ ' were also contained in this subgroup, which implies that these excellent seedlings might be progenies of these cultivars. Presumably, 'Stuart' might be the parent of 'Gloria Grande' [41]. Here, 'Gloria Grande' and 'Stuart' showed a higher similarity, which provided good support for this speculation. In addition, 'Lakota' originated from 'Mahan' $\times$ 'Major', and 'Greenriver' was selected from the same woods as 'Major'. Therefore, these three cultivars were joined together. Pecan was introduced into China in the 1900s. Currently, a large number of seedling trees is spread through several provinces in China. However, the collection and genetic study of these germplasms is still insufficient. As shown in Figure 4, a relatively long genetic distance exists between cultivars and most seedling trees in China. Therefore, the hybridization between the two types of germplasms might create more genetic variation, which might be useful for cross breeding in the future.

\section{Conclusions}

Pecan is an important multipurpose tree worldwide. However, the progress of genetic study in pecan is limited by the lack of a sufficient number of accurate, convenient, and economical molecular markers. In the present study, the distribution of SSR motifs was evaluated in the pecan genome. The gSSRs densities were $1 / 4.55 \mathrm{~kb}$ ('Pawnee') to $1 / 3.65 \mathrm{~kb}$ ('87MX3-2'). In total, 60,018 primer pairs for 20,006 gSSRs were designed, and a set of 66 gSSRs were successfully validated. Thirty gSSRs were employed to analyze the genetic diversity and progeny relationship between pecan genotypes and their cross-transferability to other Carya species. In total, 29 SSR loci showed polymorphism, and 26, 25 , and 22 gSSRs can be used in hickory, C. dabieshanensis, and C. hunanensis, respectively. We believe 
that the characterization of SSRs in the pecan genome and the new gSSRs reported here will promote the progress of genetic study and MAS research in pecan, as well as other species of the genus Carya.

Supplementary Materials: The following are available online at http://www.mdpi.com/1999-4907/11/1/61/s1, Table S1: The frequency of identified SSR motifs, Table S2: The information of primers, Table S3: The information of 66 primer pairs used in the present study, Table S4: The pedigree information of 21 cultivars.

Author Contributions: C.Z.: conceptualization, methodology, writing-original draft preparation. X.Y.: conceptualization, supervision. H.R.: data curation, writing-review and editing. J.C.: validation. J.W., W.S., and Q.F.: resources. All authors have read and agreed to the published version of the manuscript.

Funding: This work was supported by the National Natural Science Foundation of China No. 31800575, and the Fundamental Research Funds of CAF No. CAFYBB2018SY013.

Conflicts of Interest: The authors declare no conflicts of interest.

\section{References}

1. Grauke, L.J.; Wood, B.W.; Harris, M.K. Crop Vulnerability: Carya. J. Am. Soc. Hortic. Sci. 2016, 51, $653-663$. [CrossRef]

2. Gong, Y.; Pegg, R.B. Separation of ellagitannin-rich phenolics from U.S. pecans and Chinese hickory nuts using fused-core HPLC columns and their characterization. J. Agric. Food Chem. 2017, 65, 5810-5820. [CrossRef] [PubMed]

3. Zhang, C.; Yao, X.; Ren, H.; Chang, J.; Wang, K. RNA-Seq reveals flavonoid biosynthesis-related genes in pecan (Carya illinoinensis) kernels. J. Agric. Food Chem. 2019, 67, 148-158. [CrossRef] [PubMed]

4. Huang, Y.; Xiao, L.; Zhang, Z.; Zhang, R.; Wang, Z.; Huang, C.; Huang, R.; Luan, Y.; Fan, T.; Wang, J.; et al. The genomes of pecan and Chinese hickory provide insights into Carya evolution and nut nutrition. GigaScience 2019, 8, giz036. [CrossRef]

5. Hilbig, J.; Policarpi, P.D.B.; Grinevicius, V.M.A.d.S.; Mota, N.S.R.S.; Toaldo, I.M.; Luiz, M.T.B.; Pedrosa, R.C.; Block, J.M. Aqueous extract from pecan nut [Carya illinoinensis (Wangenh) C. Koch] shell show activity against breast cancer cell line MCF-7 and Ehrlich ascites tumor in Balb-C mice. J. Ethnopharmacol. 2018, 211, 256-266. [CrossRef]

6. Prado, A.C.P.d.; Manion, B.A.; Seetharaman, K.; Deschamps, F.C.; Barrera Arellano, D.; Block, J.M. Relationship between antioxidant properties and chemical composition of the oil and the shell of pecan nuts [Carya illinoinensis (Wangenh) C. Koch]. Ind. Crops Prod. 2013, 45, 64-73. [CrossRef]

7. Qin, L.; Qian, H.; He, Y. Microbial lipid production from enzymatic hydrolysate of pecan nutshell pretreated by combined pretreatment. Appl. Biochem. Biotechnol. 2017, 183, 1336-1350. [CrossRef]

8. Villarreal-Lozoya, J.E.; Lombardini, L.; Cisneros-Zevallos, L. Phytochemical constituents and antioxidant capacity of different pecan [Carya illinoinensis (Wangenh.) K. Koch] cultivars. Food Chem. 2007, 102, 1241-1249. [CrossRef]

9. Zhang, C.; Yao, X.; Ren, H.; Wang, K.; Chang, J. Isolation and characterization of three chalcone synthase genes in pecan (Carya illinoinensis). Biomolecules 2019, 9, 236. [CrossRef]

10. Vendrame, W.A.; Kochert, G.; Wetzstein, H.Y. AFLP analysis of variation in pecan somatic embryos. Plant Cell Rep. 1999, 18, 853-857. [CrossRef]

11. Beedanagari, S.R.; Dove, S.K.; Wood, B.W.; Conner, P.J. A first linkage map of pecan cultivars based on RAPD and AFLP markers. Theor. Appl. Genet. 2005, 110, 1127-1137. [CrossRef] [PubMed]

12. Jia, X.D.; Wang, T.; Zhai, M.; Li, Y.R.; Guo, Z.R. Genetic diversity and identification of Chinese-grown pecan using ISSR and SSR markers. Molecules 2011, 16, 10078-10092. [CrossRef] [PubMed]

13. Grauke, L.J.; Iqbal, M.J.; Reddy, A.S.; Thompson, T.E. Developing microsatellite DNA markers in pecan. J. Am. Soc. Hortic. Sci. 2003, 128, 374-380. [CrossRef]

14. Bentley, N.; Grauke, L.J.; Klein, P. Genotyping by sequencing (GBS) and SNP marker analysis of diverse accessions of pecan (Carya illinoinensis). Tree Genet. Genom. 2019, 15, 8. [CrossRef]

15. Bharti, R.; Kumar, S.; Parekh, M.J. Development of genomic simple sequence repeat (gSSR) markers in cumin and their application in diversity analyses and cross-transferability. Ind. Crops Prod. 2018, 111, 158-164. [CrossRef]

16. Vieira, M.L.; Santini, L.; Diniz, A.L.; Munhoz Cde, F. Microsatellite markers: What they mean and why they are so useful. Genet. Mol. Biol. 2016, 39, 312-328. [CrossRef] 
17. Zhong, Y.; Yang, A.; Li, Z.; Zhang, H.; Liu, L.; Wu, Z.; Li, Y.; Liu, T.; Xu, M.; Yu, F. Genetic diversity and population genetic structure of Cinnamomum camphora in south China revealed by EST-SSR markers. Forests 2019, 10, 1019. [CrossRef]

18. Grauke, L.J.; Mendoza-Herrera, M.A.; Binzel, M.L. Plastid microsatellite markers in Carya. Acta Hortic. 2010, 859, 237-246. [CrossRef]

19. Grauke, L.J.; Mendoza-Herrera, M.A.; Miller, A.J.; Wood, B.W. Geographic patterns of genetic variation in native pecans. Tree Genet. Genom. 2011, 7, 917. [CrossRef]

20. Li, J.; Zeng, Y.; Shen, D.; Xia, G.; Huang, Y.; Huang, Y.; Chang, J.; Huang, J.; Wang, Z. Development of SSR markers in hickory (Carya cathayensis Sarg.) and their transferability to other species of Carya. Curr. Genom. 2014, 15, 357-379. [CrossRef]

21. Conner, P.J. Roadblocks and hindrances to the development of molecular tools in pecan (Carya illinoinensis): A breeder's perspective. Acta Hortic. 2015, 1070, 83-87. [CrossRef]

22. Wang, L.; Wang, B.; Du, Q.; Chen, J.; Tian, J.; Yang, X.; Zhang, D. Allelic variation in PtoPsbW associated with photosynthesis, growth, and wood properties in Populus tomentosa. Mol. Genet. Genom. 2016, 292, 1-15. [CrossRef] [PubMed]

23. Zhang, M.; Zhou, C.; Song, Z.; Weng, Q.; Li, M.; Ji, H.; Mo, X.; Huang, H.; Lu, W.; Luo, J. The first identification of genomic loci in plants associated with resistance to galling insects: A case study inEucalyptusL'Hér. (Myrtaceae). Sci. Rep. 2018, 8, 2319. [CrossRef] [PubMed]

24. Baison, J.; Vidalis, A.; Zhou, L.; Chen, Z.Q.; Li, Z.; Sillanpää, M.J.; Bernhardsson, C.; Scofield, D.; Forsberg, N.; Grahn, T.; et al. Genome-wide association study identified novel candidate loci affecting wood formation in Norway spruce. Plant J. 2019, 100, 83-100. [CrossRef]

25. Cao, K.; Zhou, Z.; Wang, Q.; Guo, J.; Zhao, P.; Zhu, G.; Fang, W.; Chen, C.; Wang, X.; Wang, X.; et al. Genome-wide association study of 12 agronomic traits in peach. Nat. Commun. 2016, 7, 13246. [CrossRef]

26. Müller, B.S.F.; de Almeida Filho, J.E.; Lima, B.M.; Garcia, C.C.; Missiaggia, A.; Aguiar, A.M.; Takahashi, E.; Kirst, M.; Gezan, S.A.; Silva-Junior, O.B.; et al. Independent and Joint-GWAS for growth traits in Eucalyptus by assembling genome-wide data for 3373 individuals across four breeding populations. New Phytol. 2019, 221, 818-833. [CrossRef]

27. Xu, L.Y.; Wang, L.Y.; Wei, K.; Tan, L.Q.; Su, J.J.; Cheng, H. High-density SNP linkage map construction and QTL mapping for flavonoid-related traits in a tea plant (Camellia sinensis) using 2b-RAD sequencing. BMC Genom. 2018, 19, 955. [CrossRef]

28. Jenkins, J.; Wilson, B.; Grimwood, J.; Schmutz, J.; Grauke, L.J. Twoards a reference pecan genome sequence. Acta Hortic. 2015, 1070, 101-108. [CrossRef]

29. Jia, Z.; Wang, G.; Xuan, J.; Zhang, J.; Zhai, M.; Jia, X.; Guo, Z.; Li, M. Comparative transcriptome analysis of pecan female and male inflorescences. Russ. J. Plant Physiol. 2018, 65, 186-196. [CrossRef]

30. Liu, S.; An, Y.; Li, F.; Li, S.; Liu, L.; Zhou, Q.; Zhao, S.; Wei, C. Genome-wide identification of simple sequence repeats and development of polymorphic SSR markers for genetic studies in tea plant (Camellia sinensis). Mol. Breed. 2018, 38, 59. [CrossRef]

31. Zhao, H.; Yang, L.; Peng, Z.; Sun, H.; Yue, X.; Lou, Y.; Dong, L.; Wang, L.; Gao, Z. Developing genome-wide microsatellite markers of bamboo and their applications on molecular marker assisted taxonomy for accessions in the genus Phyllostachys. Sci. Rep. 2015, 5, 8018. [CrossRef] [PubMed]

32. Wu, J.; Gu, Y.Q.; Hu, Y.; You, F.M.; Dandekar, A.M.; Leslie, C.A.; Aradhya, M.; Dvorak, J.; Luo, M.C. Characterizing the walnut genome through analyses of BAC end sequences. Plant Mol. Biol. 2012, 78, 95-107. [CrossRef] [PubMed]

33. Fu, P.C.; Zhang, Y.Z.; Ya, H.Y.; Gao, Q.B. Characterization of SSR genomic abundance and identification of SSR markers for population genetics in Chinese jujube (Ziziphus jujuba Mill.). PeerJ 2016, 4, e1735. [CrossRef] [PubMed]

34. Xiao, J.; Zhao, J.; Liu, M.; Liu, P.; Dai, L.; Zhao, Z. Genome-wide characterization of simple sequence repeat (SSR) loci in Chinese jujube and jujube SSR primer transferability. PLoS ONE 2015, 10, e0127812. [CrossRef]

35. Tribhuvan, K.U.; SV, A.M.; Sharma, P.; Das, A.; Kumar, K.; Tyagi, A.; Solanke, A.U.; Sharma, R.; Jadhav, P.V. Identification of genomic SSRs in cluster bean (Cyamopsis tetragonoloba) and demonstration of their utility in genetic diversity analysis. Ind. Crops Prod. 2019, 133, 221-231. [CrossRef] 
36. Huang, C.; Yin, Q.; Khadka, D.; Meng, K.; Fan, Q.; Chen, S.; Liao, W. Identification and development of microsatellite (SSRs) makers of Exbucklandia (HAMAMELIDACEAE) by high-throughput sequencing. Mol. Biol. Rep. 2019, 46, 3381-3386. [CrossRef]

37. Zaloğlu, S.; Kafkas, S.; Doğan, Y.; Güney, M. Development and characterization of SSR markers from pistachio (Pistacia vera L.) and their transferability to eight Pistacia species. Sci. Hortic. 2015, 189, 94-103. [CrossRef]

38. Xu, X.; Zhou, C.; Zhang, Y.; Zhang, W.; Gan, X.; Zhang, H.; Guo, Y.; Gan, S. A novel set of 223 EST-SSR markers in Casuarina L. ex Adans.: Polymorphisms, cross-species transferability, and utility for commercial clone genotyping. Tree Genet. Genomes 2018, 14, 30. [CrossRef]

39. Yan, Z.; Wu, F.; Luo, K.; Zhao, Y.; Yan, Q.; Zhang, Y.; Wang, Y.; Zhang, J. Cross-species transferability of EST-SSR markers developed from the transcriptome of Melilotus and their application to population genetics research. Sci. Rep. 2017, 7, 17959. [CrossRef]

40. Zhang, J.B.; Li, R.Q.; Xiang, X.G.; Manchester, S.R.; Lin, L.; Wang, W.; Wen, J.; Chen, Z.D. Integrated fossil and molecular data reveal the biogeographic diversification of the eastern asian-eastern north american disjunct hickory genus (Carya Nutt.). PLoS ONE 2013, 8, e70449. [CrossRef]

41. Conner, P.J.; Wood, B.W. Identification of pecan cultivars and their genetic relatedness as determined by randomly amplified polymorphic DNA analysis. J. Am. Soc. Hortic. Sci. 2001, 126, 474-480. [CrossRef]

(C) 2020 by the authors. Licensee MDPI, Basel, Switzerland. This article is an open access article distributed under the terms and conditions of the Creative Commons Attribution (CC BY) license (http://creativecommons.org/licenses/by/4.0/). 